Kong. Res. J. 2(1) : 1-3, 2015

ISSN 2349-2694

Kongunadu Arts and Science College, Coimbatore.

\title{
PREPARATION OF MESOSCOPIC STRUCTURE POLY METHYL METHACRYLATE THIN FILMS FOR AFM DATA STORAGE DEVICES.
}

\author{
Chandar Shekar, Ba ${ }^{*}$, S. Sathisha, Sulana Sundari ${ }^{b}$, S.Sunnithab $^{\mathrm{b}}$ and C. Sharmilac \\ a Department of Physics, Kongunadu Arts and Science College, Coimbatore, Tamil Nadu. \\ ${ }^{\mathrm{b}}$ NEAR foundation, The Nilgiris, Tamil Nadu. \\ c Department of Physics, PSGR Krishnammal College for Women, Coimbatore, Tamil Nadu. \\ *E-mail: chandar.bellan@ gmail.com
}

\begin{abstract}
Poly methyl methacrylate (PMMA) thin films were prepared by dip coating method. Benzene was used as a solvent to prepare PMMA thin films for the time periods ranging from $1 \mathrm{~min}$. to $1 \mathrm{~h}$. The thickness of the films deposited was measured by using an electronic thickness measuring instrument (Tesatronic-TTD-20). Fourier Transform Infrared spectrum was used to identify the above said films. X-ray diffraction spectra indicated the predominantly amorphous nature of the films. Surface morphology of the coated films studied by using scanning electron microscope (SEM) indicated the absence of any pits, cracks and pin holes in the surface. Both as grown and annealed films showed smooth and amorphous structures. The closer SEM inspection revealed the presence of self assembled mesoscopic cells. The mesoscopic structure PMMA thin films could be used as an AFM-based data storage which is promising alternative to conventional magnetic data storage because it offers great potential for considerable storage density improvements.
\end{abstract}

Key words: Polymethyl methaacrylate, Dip coating, Morphology, Mesoscopic, FTIR, SEM .

\section{INTRODUCTION}

Thin films of polymer have attracted the attention of researchers mainly because of their unique properties, resistivity, electrical properties and their ease of processing and fabrication. The important advantages of polymer thin films are that they can be prepared easily and at low cost. Poly methyl methacrylate (PMMA) is one of the promising representatives of polymeric materials and there are numerous proposals for its application as dielectric in organic thin film transistors (OTFTs) (Puigdollers et al.,2004; Uemura et al., 2003; Chandar Shekar et al., 2004), sensors (Ponelyte and Palevicius, 2014) as optical lenses in cameras and optical fibers (Nakata et al., 2004; Yang et al., 2004) . Extensive work has been carried out on synthesis, preparation and various properties such as morphology, dielectric, optical and aging behavior of PMMA films (Sakai et al., 2009; Konno et al., 2009; Kim et al., 2009; Mabrook et al., 2009) . In the present work an attempt has been made to prepare PMMA thin films of suitable thickness by a simple dip coating method which could be used in AFM data storage devices.

\section{MATERIALS AND METHODS}

PMMA polymer obtained from Sigma-Aldrich was used without further purification to form the insulator layer. The cleaned glass plates were held vertically above the PMMA solution (concentration of $2.5 \%$ with benzene as a solvent) by means of mechanical arrangement capable of slow and steady vertical movement. The substrates were immersed in the solution at room temperature for different time period (1 min to $1 \mathrm{~h}$ ). After withdrawal from the solution, the substrates with the deposited film was dried in the atmosphere for 45 minutes and then kept inside an oven at $373 \mathrm{~K}$ for $1 \mathrm{~h}$. The thickness of the coated films was measure by using an electronic thickness measuring instrument (Tesatronic-TTD20). The PMMA films coated were identified by using FTIR spectrometer. The structure of the deposited PMMA films was studied by using XRD. The surface morphologies of the deposited PMMA films were investigated by using Scanning Electron Microscope.

\section{RESULTS AND DISCUSSION}

The functional groups present in the deposited polymer film were identified by FTIR spectrum. Figs $1 \mathrm{a}, \mathrm{b}$ shows the FTIR spectrum of PMMA thin films of thickness $360 \mathrm{~nm}$ and $1810 \mathrm{~nm}$ respectively.

The bands observed at $677 \mathrm{~cm}^{-1}$ and $750 \mathrm{~cm}^{-1}$ are assigned to $\mathrm{OH}$ bending. The bands at $1060 \mathrm{~cm}^{-1}$, $1245 \mathrm{~cm}^{-1}, 1730 \mathrm{~cm}^{-1}$ and $2926 \mathrm{~cm}^{-1}$ are respectively assigned to $v(\mathrm{C}-\mathrm{O})$ stretching vibration, wagging vibration of $\mathrm{C}-\mathrm{H}, \mathrm{C}=\mathrm{O}$ stretching and $\mathrm{C}-\mathrm{H}$ stretching. 
The X-ray diffraction pattern of PMMA thin films of thickness $360 \mathrm{~nm}$ and $1810 \mathrm{~nm}$ are presented in the Figs. 2a, b.
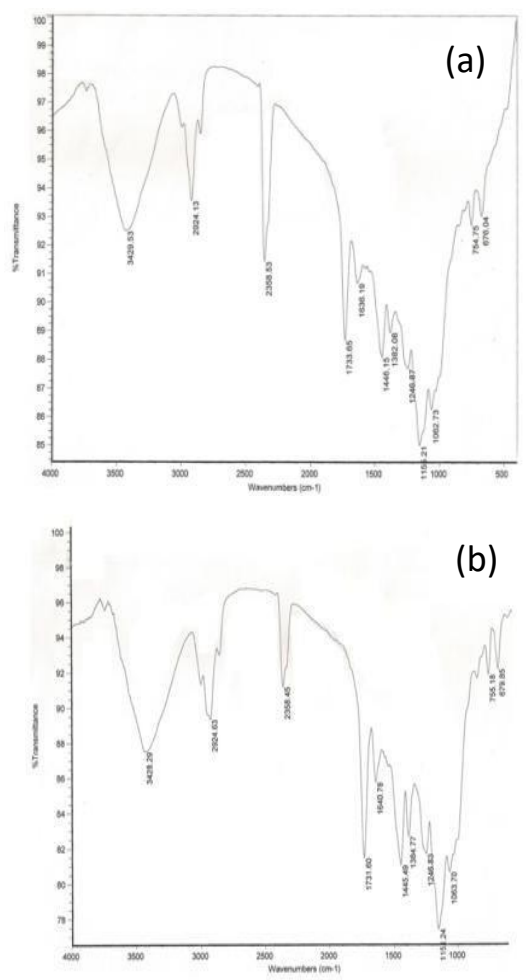

Fig. 1. FTIR spectrum of PMMA film of thickness a) $360 \mathrm{~nm}$ and b) $1810 \mathrm{~nm}$.
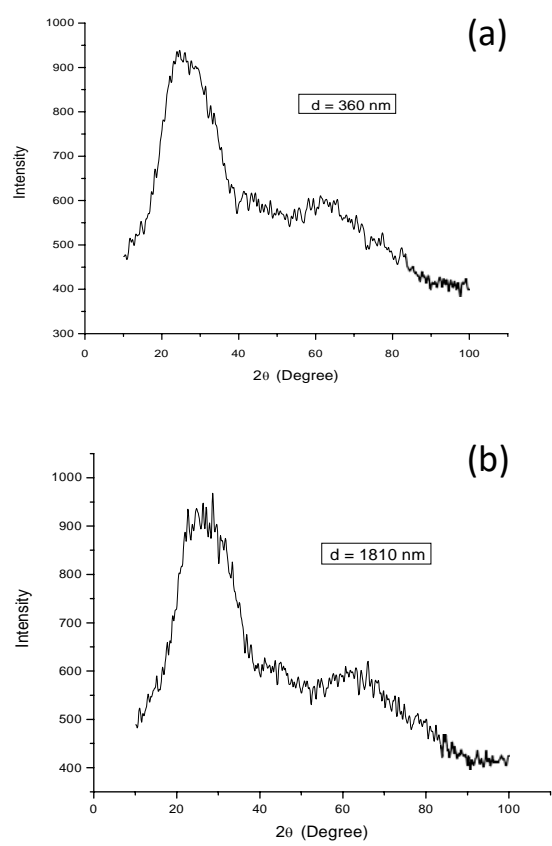

Fig 2. XRD pattern of PMMA thin film of thickness a) $360 \mathrm{~nm}$ and b) $1810 \mathrm{~nm}$
The $x$-ray diffraction pattern shows large diffraction maximum that decreases at large diffraction angles indicates the amorphous nature of the film. The shape of the first main maximum indicates the ordered packing of the polymer chains. The intensity and shape of the second maxima are related to the effect inside the main chains (Chandar Shekar et al., 2013) . The broad humps observed in the XRD spectrum indicate the presence of crystallites of very low dimensions. The absence of any prominent peaks in the spectrum indicates the predominantly amorphous nature of the films.

Figs. 3a, $b$ shows the SEM image of PMMA films of thickness $360 \mathrm{~nm}$ and $1810 \mathrm{~nm}$ respectively.

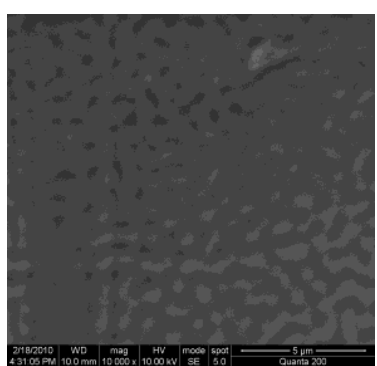

(a)

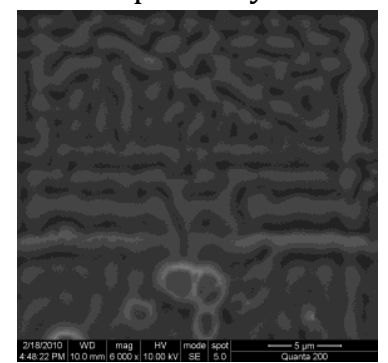

(b)
Fig. 3. SEM Micrographs of PMMA thin films of thickness a) $360 \mathrm{~nm}$ and b) $1810 \mathrm{~nm}$.

The SEM analysis revealed self assembled mesoscopic structured films as presented in the figure, when deposited under dip coating process. The formation of the mesoscopic structures may be described with the help of the considerations presented below. Due to fast external drying, all solvents which leave the solution are immediately removed from the film. Then at an early stage of the evaporation process, a polymer rich layer is formed. The thickness of such layers may be of the order of mesoscopic scale range. The dip coating process presented in this work is simple, highly reproducible and permits fabrication of large areas of mesoscopic structured films, which have a potential as membranes, long period gratings and photonic molecules. The surface morphology is quite homogenous and amorphous in nature without any pits, cracks and pinholes. The mesoscopic structures obtained for the very thin film of PMMA could be used as an AFM-based data storage which is promising alternative to conventional magnetic data storage because it offers great potential for considerable storage density improvements.

\section{CONCLUSION}

The FTIR analysis indicated the absence of any impurity in the PMMA thin films. The X-ray diffraction pattern revealed the amorphous nature of 
the films studied. The SEM analysis revealed the phenomenon of self assembly on the mesoscopic scale. The dip coating process presented in this work is simple, highly reproducible and permits fabrication of large areas of mesoscopic structured films. The mesoscopic structured films have the potential as membranes, long period gratings, photonic molecules and AFM based data storage system.

\section{REFERENCES}

Chandar Shekar, B., M. Na, J. Lee and S.W. Rhee, (2004). Mol. Cryst. Liq. Cryst. 424: 43-53.

Chandar Shekar, B., S. Sathisha and R. Sengoden, (2013). Physics Procedia. 49: 145 - 157.

Kim, T.G., E.H. Jeong, S.C. Lim, S.H. Kim, G.H. Kim, S.H. Kim, H.Y. Jeon and J.H. Youk, (2009). Synthetic Metals 159: 749-753.

Konno, K., H. Sakai, T. Matsushima and H. Murata, (2009). Thin Solid Films 518: 534-536.
Mabrook, M.F., A.S. Jombert, S.E. Machin, C. Pearson, D. Kolb, K.S. Coleman, D.A. Zeze and M.C. Petty, (2009). Materials Science and Engineering: $B$ 159-160: 14-17.

Nakata, K., M. Ohji, Y. Ikuno, S. Kusaka, F. Gomi, M. Kamei, D.F. Ross and Y. Tano, Am. J. Ophthalmol. 137: 760-762.

Ponelyte, S. and A. Palevicius, (2014). Sensors 14: 6910-6921.

Puigdollers, J., C.V.I. Martin, A. Orpella, M. Vetter and R. Alcubilla, (2004). J. Non-Crystalline Solids 338-340: 617-621.

Sakai, H., K. Konno and H. Murata, (2009). Thin Solid Films 518: 510-513.

Uemura, S., M. Yoshida, S. Hoshino, T. Kodzasa and T. Kamata, (2003). Thin Solid Films 438-439: 378 $-381$.

Yang, D.X., J. Yu, X. Tao and H. Tam, (2009). Materials Science and Engineering A 364: 256-259. 